\title{
PERBANDINGAN HASIL BELAJAR ANTARA MODEL PEMBELAJARAN EXAMPLES NON EXAMPLES DENGAN PEMBELAJARAN SAINTIFIK
}

\author{
${ }^{1}$ Ahen Hestavia, ${ }^{2}$ Syafdi Maizora, ${ }^{3}$ Nurul Astuty Yensy \\ 1,2,3 Program Studi Pendidikan Matematika JPMIPA FKIP Universitas Bengkulu \\ Email : ${ }^{1}$ ahenhestavia@gmail.com, ${ }^{2}$ syafdiichiemaizora@unib.ac.id, \\ ${ }^{3}$ nurulastutyyensy@yahoo.com
}

\begin{abstract}
Abstrak
Penelitian ini bertujuan untuk mengetahui perbandingan model pembelajaran Examples Non Examples dengan pendekatan saintifik terhadap hasil belajar matematika siswa kelas VII SMP Negeri 14 Kota Bengkulu. Populasi pada penelitian ini adalah siswa kelas VII SMP Negeri 14 Kota Bengkulu, sedangkan sampelnya yaitu siswa kelas VII.3 sebagai kelas eksperimen 2 dengan menerapkan pembelajaran saintifik dan siswa kelas VII.4 sebagai kelas eksperimen 1 dengan menerapkan model pembelajaran Examples Non Examples. Untuk analisis data menggunakan uji-t dengan data berdistribusi normal dan homogen. Berdasarkan hasil penelitian diperoleh nilai rata-rata siswa yang diajar dengan menggunakan model pembelajaran Examples Non Examples lebih tinggi dibandingkan dengan nilai rata-rata siswa yang diajar tanpa menggunakan pembelajaran Examples Non Examples. Hasil uji hipotesis diperoleh $\mathrm{t}_{\text {hitung }}>\mathrm{t}_{\text {tabel }}$ jadi 11,7 $>1,698$ dengan $\alpha=5 \%$. sehingga $\mathrm{H}_{0}$ ditolak maka dapat disimpulkan bahwa terdapat perbandingan model pembelajaran Examples Non Examples dengan pendekatan saintifik terhadap hasil belajar matematika siswa kelas VII SMP Negeri 14 Kota Bengkulu.
\end{abstract}

Kata kunci: Hasil Belajar, Examples Non Examples, saintifik

\begin{abstract}
This research aimed to know the comparison learning Examples Non Examples with scientific learning on the study's result of mathematics for student grade VII SMP Negeri 14 Kota Bengkulu. This research population was students grade VII SMP Negeri 14 Kota Bengkulu where as white the sample was student grade VII.3 as experiment 2 class by applying scientific learning and student grade VII.4 as experiment 1 class by applying learning Examples Non Examples. For data analysis using ttest with normal distribution of data and homogeneous. Based on the results obtained by the average value of students being taught by using learning Examples Non Examples is higher than the average student is taught without learning Examples Non Examples. Hypothesis test result obtained value $\mathrm{t}_{\text {count }}$ $>\mathrm{t}_{\text {table }}$ then $11,7>1,698$ with $\alpha=5 \%$. So that $\mathrm{H}_{0}$ was rejected and it can be comparison that there was comparison of learning Examples Non Examples with scientific learning on the study's result of mathematics for student grade VII SMP Negeri 14 Kota Bengkulu.
\end{abstract}

Keyword: Study's result, Examples Non Examples, Scientific

\section{PENDAHULUAN}

Matematika merupakan salah satu mata pelajaran yang dipelajari di semua bidang ilmu pengetahuan. Ini berati bahwa peran matematika di dunia pendidikan sangat mempengaruhi perkembangan dimasa yang akan datang terutama dibidang ilmu pengetahuan dan ilmu pendidikan yang 
semakin maju tiap tahunnya. Guru juga menjadi pendorong dalam memotivasi untuk belajar dan kreatif dalam merencanakan pembelajaran sehingga terjadi umpan balik anatar guru dan siswa dalam proses pembelajaran.

Pada pembelajaran matematika pemilihan model pembelajaran sangat penting, ada banyak model pembelajaran yang diterapkan oleh guru di seluruh Indonesia salah satunya yaitu model pembelajaran kooperatif. Pembelajaran kooperatif merupakan suatu pembelajaran kelompok dengan jumlah kelompoknya terdiri dari 2-5 orang. Model pembelajaran kooperatif yang dapat di gunakan oleh guru untuk bahan mengajar salah satunya adalah model pembelajaran kooperatif tipe Examples Non Example. Model pembelajaran ini menuntut siswa agar pandai menganalisi suatu gambar dari gambar yang merupakan contoh dari materi dan bukan gambar contoh dari materi yang dijelaskan, dan siswa juga di ajarkan untuk berfikir keritis terhadap memecahkan suatu masalah, dan model pembelajaran ini juga memiliki kaitan dengan pembelajaran saintifik yang diterapkan kurikulum 2013, yaitu siswa dituntut untuk berfikir kritis dan guru hanya sebagai fasilitator saja saat pembelajaran berlangsung. Dalam buku Shohimin (2014:120), Komalasari menyebutkan bahwa examples non examples adalah model pembelajaran yang membelajarkan murid terhadap permasalahan yang ada di sekitar melalui analisis contoh contoh berupa gambar - gambar, foto, dan kasus yang bermuatan masalah. Murid diarahkan untuk mengidentifikasi masalah, mencari alternatif pemecahan masalah dan menentukan cara pemecahan masalah yang paling efektif, serta melakukan tindak lanjut.
Matematika merupakan salah satu mata pelajaran yang dipelajari di semua bidang ilmu pengetahuan. Ini berati bahwa peran matematika di dunia pendidikan sangat mempengaruhi perkembangan dimasa yang akan datang terutama dibidang ilmu pengetahuan dan ilmu pendidikan yang semakin maju tiap tahunnya. Guru juga menjadi pendorong dalam memotivasi untuk belajar dan kreatif dalam merencanakan pembelajaran sehingga terjadi umpan balik anatar guru dan siswa dalam proses pembelajaran.

Model pebelajaran Examples Non Examples menurut Lestari dan Yudhanegara (2017 : 76) adalah model pembelajaran yang mengajarkan siswa untuk belajar mengerti dan menganalisis sebuah konsep berdasarkan contoh dan bukan contoh dengan menggunakan media gambar yang bertujuan mendorong siswa untuk belajar berfikir kritis dengan jalan menyelesaikan permasalahan yang terkandung dalam contoh gambar yang disajikan. Setiap model pembelajaran pasti memiliki kelebihan dan kekurangannya tersendiri salah satunya model pembelajaran kooperatif tipe examples non examples. Huda (2017 : 234) kelebihan model pembelajaran kooperatif tipe examples non examples yaitu, (1) siswa lebih kritis dalam menganalisis gambar, (2) siswa mengetahui aplikasi dari materi berupa contoh gambar, (3) siswa diberikan kesempatan untuk mengemukakan pendapatnya, dan kelemahan model model pembelajaran kooperatif tipe examples non examples adalah tidak semua materi dapat disajikan dalam bentuk gambar, selain karena persiapannya yang terkadang membutuhkan waktu lama. Sani (2014 : 33) menjelaskan kekurangan dari model pembelajaran kooperatif tipe examples non examples ini anatar lain, (1) keterbatasan 
gambar untuk semua materi pembelajaran, karena tidak semua materi dapat disajikan dalam bentuk gambar, dan yang ke (2) model ini menghabiskan waktu yang lama, apalagi jika antusias siswa yang besar terhadap materi tersebut.

Berdasarkan pendapat sebelumnya bahwasanya tidak ada model yang tidak memiliki kekurangan ataupun kelebihan dalam proses pembelajaran berlangsung. Manfaat yang dapat dirasakan oleh siswa dalam pembelajaran berlangsung ternyata juga memiliki kelemahan dimana hal ini menuntut kemampuan seorang guru dalam menerapkan model pembelajaran dan mengawasi siswa saat pembelajaran dikelas dimulai. Cara mengatasi kelemahan pada model pembelajaran ini yaitu guru dapat memilih materi yang sesuai dengan model pembelajaran examples non examples agar siswa menjadi antusias dalam proses pembelajaran berlangsung, dan apabila waktu yang dibutuhkan kurang pada saat proses pembelajaran, maka guru akan mengurangi beberapa soal latihan yang akan diberikan dan akan dibahas diminggu selanjutnya sebelum masuk ke materi yang baru.

Model pembelajaran saintifik merupakan pembelajaran yang dilandasi pendekatan ilmiah dalam pembelajaran yang diorientasikan guna membina kemampuan siswa memecahkan masalah melalui serangkaian aktivitas inkuiri yang menuntut kemampuan berfikir kritis, berfikiri kreatif, dan berkomunikasi dalam upaya meningkatkan pemahaman siswa (Abidin, 2016 : 127).

Hosnan (2014 : 37) menjelaskan tentang langkah - langkah umum pembelajaran dengan pendekatan saintifik yaitu, menggali informasi melalui pengamatan, bertanya, percobaan, kemudian mengolah data atau informasi, menyajikan data atau informasi, dilanjutkan dengan menganalisis, menalar, kemudian menyimpulkan dan membentuk jaringan (networking).

\section{METODE}

Jenis penelitian yang digunakan dalam penelitian ini adalah penelitian eksperimen semu. Populasi dalam penelitian ini adalah semua siswa kelas VII di SMP Negeri 14 Kota Bengkulu tahun ajaran 2017/2018. Sampel penelitian ini kelas VII.4 sebagai kelas eksperimen dan kelas VII.3 sebagai kelas kontrol. Intrumen yang digunakan berbentuk soal subjektif essay 8 soal yang akan diuji coba terlebih dahulu dengan kelas yang sudah mempelajari materi yang sudah ditentukan.

Selanjutnya instrumen tersebut diuji. Untuk menguji validitas item tes digunakan rumus koefisien korelasi product moment dengan rumus :

$$
r_{x y}=\frac{N \sum x y-\left(\sum x\right)\left(\sum y\right)}{\sqrt{\left.\left\{\left(N\left(\sum x^{2}\right)-\left(\sum x\right)^{2}\right)\left(N\left(\sum y^{2}\right)-\sum y\right)^{2}\right)\right\}}}
$$

(Jakni, 2016:165)

Dengan kriteria:

Jika $r_{x y}>r_{\text {tabel }}$ maka soal valid

Jika $r_{x y}<r_{\text {tabel }}$ maka soal tidak valid

Reliabilitas

Reliabilitas adalah uatu instrument dikatakan memiliki keterandalan sempurna, manakala hasil pengukuran berkali - kali terhadap subjek yang sama selalu menunjukan hasil atau skor yang sama (Jakni, 2016:153).

Uji Reliabilitas tes hasil belajar dapat dihitung menggunakan rumus :

$$
r_{11}=\left[\frac{k}{k-1}\right]\left[1-\frac{\sum s \sigma_{h}^{2}}{\sigma_{t}^{2}}\right]
$$

(Syofian Siregar, 2014:176)

Keterangan: 
Dalam pemberian interpretasi terhadap koefisien reliabilitas tes $\left(r_{11}\right)$ digunakan kriteria sebagai berikut:

1) Apabila $0,70 \leq r \leq 0,90$ berarti tes yang sedang diuji reliabilitasnya dinyatakan telah memiliki reliabilitas yang tinggi (reliabel).

2) Apabila $0,40 \leq r \leq 0,70$ berarti tes yang sedang diuji reliabilitasnya dinyatakan telah memiliki reliabilitas yang cukup/baik.

Instrumen/soal dapat digunakan sebagai instrument dalam penelitian jika nilai koefisien korelasi berada di kategori sedang (cukup tetap/cukup baik), (Lestari dan Yudhanegara, 2017 : 214).

\section{Tingkat Kesukaran}

Tingkat kesukaran (TK) pada masing - masing butir soal dihitung dengan menggunakan rumus:

$T K=\frac{\bar{X}}{S M I}$

(Lestari dan Yudhanegara, 2017:224)

Interpretasi tingkat kesukaran yang digunakan:

Tabel 3 Kriteria Tingkat Kesukaran

\begin{tabular}{|l|c|}
\hline \multicolumn{1}{|c|}{ Interval } & Tingkat kesukaran \\
\hline $\mathrm{TK}=0,00$ & Terlalu sukar \\
\hline $0,00<T K \leq 0,30$ & Sukar \\
\hline $0,30<T K \leq 0,70$ & Sedang \\
\hline $0,70<T K \leq 1,00$ & Mudah \\
\hline $\mathrm{TK}=1,00$ & \multicolumn{2}{|c|}{ Terlalu mudah } \\
\hline \multicolumn{2}{|c|}{ Menurut Lestari dan Yudhanegara }
\end{tabular}

(2017:224) bahwa soal-soal yang dianggap baik adalah soal dengan tingkat kesukaran sedang yaitu dengan TK antara $0,30<T K \leq$ 0,70 .
Daya Pembeda Soal

Daya Pembeda (DP) pada masing - masing butir soal di tentukan dengan menggunakan rumus :

$D P=\frac{\bar{X}_{A}-\bar{X}_{B}}{S M I}$

(Lestari dan Yudhanegara, 2017:223-217)

interpretasi nilai DP yaitu:

Table 3 Daya Pembeda

\begin{tabular}{|c|c|}
\hline Nilai & $\begin{array}{c}\text { Interpretasi Daya } \\
\text { Pembeda }\end{array}$ \\
\hline $0,70<D P \leq 1,00$ & Sangat baik \\
\hline $0,40<D P \leq 0,70$ & Baik \\
\hline $0,20<D P \leq 0,40$ & Cukup \\
\hline $0,00<D P \leq 0,20$ & Buruk \\
\hline DP $\leq 0,00$ & Sangat buruk \\
\hline
\end{tabular}

Pada penelitian ini daya beda dikatakan baik untuk butir soal tes jika minimum besarnya 0,3 atau $D P \geq 0,3$ (Mardapi, 2012:188).

\section{Pengujian Persyaratan Analisis Uji Normalitas}

Rumus yang digunakan untuk menguji hipotesis adalah rumus chi kuadrat yaitu :

$$
\chi_{0}^{2}=\sum_{i=1}^{k} \frac{\left(f_{0}-f_{h}\right)^{2}}{f_{h}}
$$

(Sugiyono, 2012:19)

Kriteria pengujiannya adalah $\mathrm{H}_{0}$ diterima jika $X_{\text {hitung }}^{2} \leq X_{\text {tabel }}^{2}$. Sebaliknya $\mathrm{H}_{0}$ ditolak jika $X_{\text {hitung }}^{2}>X_{\text {tabel }}^{2}$. Dengan taraf nyata $5 \%$ $(\propto=0,05)$, Sugiyono $(2017: 109)$

\section{Uji Homogenitas}

Uji homogenitas dilakukan untuk mengetahui apakah kedua kelas mempunyai varians yang tidak jauh berbeda, baik kelas yang menggunakan model pembelajaran 
kooperatif tipe Examples Non Examples maupun yang menggunakan pendekatan saintifik. Jika kedua kelas mempunyai varians yang tidak jauh berbeda maka kedua kelas dikatakan homogen. Untuk melakukan uji homogenitas varians menggunakan rumus uji fisher:

$F=\frac{\text { varians terbesar }}{\text { varians terkecil }}$

(Jakni, 2017:175)

Kriteria pengujiannya adalah $\mathrm{H}_{0}$ diterima jika $F_{\text {hitung }}<F_{\text {tabel }}$. Sebaliknya $\mathrm{H}_{0}$ ditolak jika $F_{\text {hitung }} \geq F_{\text {tabel }}$, dengan taraf nyata $5 \%$ $(\propto=0,05)$, dk pembilang $=\left(n_{b}-1\right)$ dan $\mathrm{dk}$ penyebut $=\left(n_{k}-1\right)$.

\section{Pengujian Hipotesis}

Setelah selesai melaksanakan pembelajaran menggunakan model pembelajaran kooperatif tipe Examples Non Examples dan pembelajaran dengan Pendekatan Saintifik, kemudian akan diberikan tes dengan menggunakan lembar tes. Dari tes tersebut diperoleh data hasil belajar matematika siswa. Data yang telah diperoleh dianalisis dengan uji hipotesis menggunakan uji-t untuk sampel independen. Adapun rumusnya sebagai berikut:

$$
t=\frac{X_{1}-X_{2}}{\sqrt{\frac{S_{1}^{2}}{n_{1}}+\frac{S_{2}^{2}}{n_{2}}}}
$$

(Sugiyono, 2017:138)

Kriteria pengujiannya adalah $\mathrm{H}_{0}$ diterima jika $t \leq t_{\text {tabel }}$. Sebaliknya $\mathrm{H}_{0}$ ditolak jika

$t>t_{\text {tabel }}$. Taraf signifikan $\propto=0,05$ dan derajat kebebasan $\mathrm{db}=n_{1}+n_{2}-2$.

\section{HASIL DAN PEMBAHASAN}

Penelitian dilaksanakan mulai tanggal 2 April sampai dengan 9 Mei 2018. Di SMP
Negeri 14 kota Bengkulu, peserta didik belajar matematika 2 kali dalam satu minggu. Satu pertemuan terdiri dari 2 dan 3 jam pelajaran sehingga 5 jam pelajaran dalam satu minggu. Alokasi waktunya 40 menit untuk satu jam pelajaran.

Dari hasil observasi dan wawancara diperoleh kedua sampel yaitu kelas VII.3 dan VII.4 hal ini dikarena nilai rata-rata ulangan harian yang memiliki varian tidak jauh berbeda. Berdasarkan nilai rata-rata tersebut ditentukan bahwa kelas VII.4 sebagai kelas eksperimen 1 yaitu yang diberikan perlakuan dengan pembelajaran menggunakan model pembelajaran examples non examples dengan pendekatan saintifik, sedangkan kelas VII.3 sebagai kelas eksperimen 2 dengan pembelajaran menggunakan pendekatan saintifik yang tanpa menggunakan model pembelajaran examples non examples.

Sebelum tes diberikan kepada kedua sampel, terlebih dahulu soal tes diuji validitas oleh validator. Validator yang menilai tes yang akan diuji coba ada 2 orang yaitu guru matematika SMP Negeri 14 Kota Bengkulu dan dosen pedidikan matematika. Berdasarkan pertimbangan ahli, semua butiran soal telah valid tetapi ada beberapa soal yang harus disajikan dengan jelas. Setelah dilakukan uji validasi dengan validator ternyata soal dapat diuji cobakan terhadap sampel lain yang sudah mempelajari materi sifat-sifat bangun datar segiempat dan dilakukan uji coba instrumen belajar yang berbentuk soal subjektif berupa essay dengan jumlah 8 buah soal.

Tabel Hasil Analisis Uji Coba Soal

\begin{tabular}{|c|c|c|c|c|}
\hline \multirow{2}{*}{$\begin{array}{c}\text { Nomo } \\
\text { r Soal }\end{array}$} & $\begin{array}{c}\text { Validita } \\
\text { s }\end{array}$ & $\begin{array}{c}\text { Reliabilita } \\
\text { s }\end{array}$ & $\begin{array}{c}\text { Taraf } \\
\text { Kesukara } \\
\mathbf{n}\end{array}$ & $\begin{array}{c}\text { Daya } \\
\text { Beda }\end{array}$ \\
\cline { 2 - 4 } & Ket & Ket & Ket & Ket \\
\hline 1 & Valid & \multirow{2}{*}{ Baik } & Mudah & Baik \\
\cline { 2 - 2 } 2 & Valid & & Sedang & Cukup \\
\hline
\end{tabular}




\begin{tabular}{|c|c|c|c|}
\hline 3 & Valid & Sedang & Cukup \\
\hline 4 & Valid & Mudah & Baik \\
\hline 5 & Valid & Sedang & Baik \\
\hline 6 & Valid & Sedang & Cukup \\
\hline 7 & Valid & Sedang & Cukup \\
\hline 8 & Valid & Sedang & Baik \\
\hline
\end{tabular}

Rekapitulasi hasil uji coba soal diatas diketahui bahwa semua soal dapat digunakan dengan kriteria ketuntasan validitas, reliabilitas, tingkat kesukaran dan daya pembeda, semua soal direvisi dengan penggunaan tata bahasa yang baik dan benar, maka semua soal dapat di uji cobakan.

\section{Analisis Deskriptif Hasil Belajar Siswa Kelas eksperimen}

Setelah selesai pembelajaran selama $7 \mathrm{kali}$ pertemuan dikelas eksperimen, diberikan tes akhir (posttest). Soal posttest yang diberikan berupa soal subjektif essay, yang diikuti oleh 31 peserta didik. Pemberian posttest ini bertujuan untuk mengetahui nilai hasil belajar siswa. Rata - rata hasil belajar kelas eksperimen 80,48 dari jumlah siswa 31 orang dan skewness 0,343 ini berarti nilai skewness (mendekati nol) berdistribusi normal. Untuk lebih jelasnya lihat pada kurva sebagai berikut :

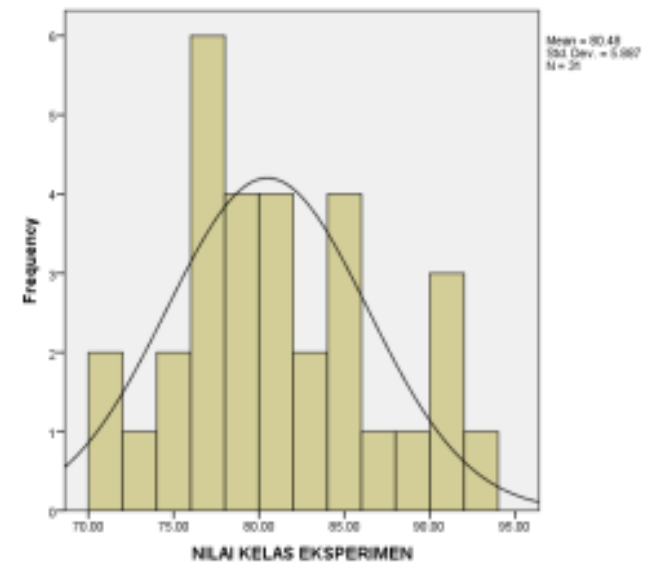

\section{Gambar 4 Kurva Histrogram Distribusi Kenormalan Kelas Eksperimen 1}

\section{Analisis Deskriptif Hasil Belajar Siswa Kelas Kontrol}

Setelah selesai pembelajaran selama 7 kali pertemuan dikelas kontrol, diberikan tes akhir (posttest). Soal posttest yang diberikan berupa soal subjektif essay, yang diikuti oleh 30 peserta didik. Pemberian posttest ini bertujuan untuk mengetahui nilai hasil belajar siswa. Rata - rata hasil belajar kelas eksperimen 40,37 dari jumlah siswa 30 orang dan skewness 0,657 ini berarti nilai skewness (mendekati nol) berdistribusi normal. Untuk lebih jelasnya lihat pada kurva sebagai berikut :

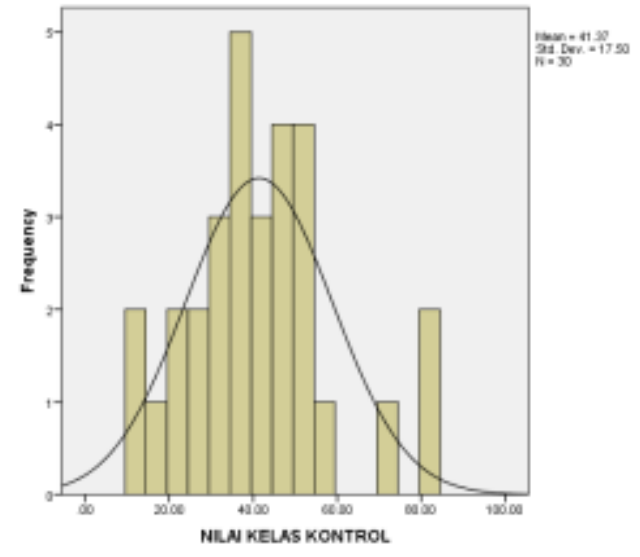

\section{Gambar 4 Kurva Histrogram Distribusi Kenormalan Kelas Eksperimen 2}

Rekapitulasi hasil uji normalitas kelas eksperimen dan kelas eksperimen 21 dengan pengujian chi-kuadrat. Sampel berdistribusi normal karena $\chi_{\text {hitung }}^{2}<\chi_{\text {tabel }}^{2}$ dimana nilai $\chi_{\text {hitung }}^{2}$ kelas eksperimen adalah 201847 dan $\chi_{\text {hitung }}^{2}$ pada kelas kontrol yaitu 60217 dengan nilai $\chi_{\text {tabel }}^{2}$ sebesar 11,070 pada taraf signifikan $5 \%$ sehingga berdasarkan kriteria pengujian $H_{0}$ diterima. Jadi, data nilai posttest pada kelas eksperimen 1 dan kelas eksperimen 2 berdistribusi normal. Rekapitulasi hasil uji homogenitas pengujian menggunakan uji $f$. kedua kelas tidak homogen (varians tidak homogen) Kriteria pengujian yang digunakan adalah jika $F_{\text {hitung }}<F_{\text {tabel }}$ maka $H_{0}$ diterima. 
Sebaliknya jika $F_{\text {hitung }} \geq F_{\text {tabel }}$ maka $H_{0}$ ditolak. Taraf nyata yang digunakan adalah $5 \%$ $(0,05)$. diketahui bahwa nilai $F_{\text {hitung }} \geq F_{\text {tabel }}$ yaitu $8.8355 \geq 1,85$, sehingga berdasarkan kriteria pengujian $H_{0}$ ditolak. Jadi, data nilai posttest kedua kelas tidak homogen.

Pengujian hipotesis dengan uji t, hasil pengujian kelas eksperimen dan kelas kontrol dengan nilai $t_{\text {hitung }}=11,7$ dan nilai $\quad t_{\text {tabel }}=1,698$ dinyatakan bahwa $t_{\text {hitung }}>F_{\text {tabel }}$ yaitu 11,7 $>$ 1.698, sehingga berdasarkan kriteria pengujian $H_{0}$ ditolak. Dapat disimpulkan bahwa adannya perbandingan antara hasil belajar antara model pembelajaran examples non examples dengan pendekatan saintifik dan pembelajaran yang hanya menggunakan pendekatan saintifik.

\section{Tabel 4. Perbandingan hasil belajar}

\begin{tabular}{|c|c|}
\hline Kelas Eksperimen & Kelas Kontrol \\
\hline 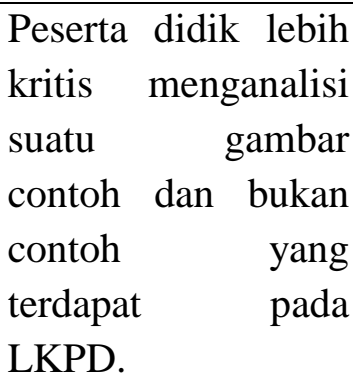 & $\begin{array}{lr}\text { Peserta didik hanya } \\
\text { mengerti gabar dari } \\
\text { materi } \\
\text { terdapat } \\
\text { LKPD. }\end{array}$ \\
\hline $\begin{array}{l}\text { Peserta didik lebih } \\
\text { aktif. }\end{array}$ & $\begin{array}{l}\text { Peserta didik } \\
\text { cenderung pasif. }\end{array}$ \\
\hline $\begin{array}{l}\text { Peserta didik berani } \\
\text { mengungkapkan } \\
\text { pendapatnya. }\end{array}$ & $\begin{array}{l}\text { Peserta didik berani } \\
\text { mengungkakpkan } \\
\text { pendapat apabila di } \\
\text { perintah oleh guru. }\end{array}$ \\
\hline
\end{tabular}

Berdasarkan hasil penelitian pembelajaran pada kelas eksperimen 1 yang menggunakan model pembelajaran examples non examples menggunakan kartu examples non examples. Penggunaan kartu merupakan salah satu usaha untuk mencapai tujuan pembelajaran. Dengan menggunakan model pembelajaran beserta kartu examples non examples diharapkan dapat memancing semangat, motivasi dan minat daya tarik anak untuk semangat belajar.

Kelas eksperimen 1 diterapkan model pembelajaran kooperatif tipe examples non examples dengan pendekatan saintifik, pembelajaran ini mengharuskan peserta didik untuk memahami dari materi contoh dan bukan contoh dengan menerapkan konsep pembelajaran dengan pendekatan saintifik dari situasi yang terdapat pada LKPD. sedangkan pada kelas kontrol hanya diberikan pendekatan saintifik, pada tipe ini peneliti mengarahkan peserta didik dengan komponen-komponen saintifik. Kelas eksperimen 1 yang menggunakan model pembelajaran kooperatif tipe Examples Non Examples dengan pendekatan saintifik pada LKPD lebih terstruktur, hal ini dikarenakan pada bagian mengamati peserta didik dapat membedakan mana bagian dari materi yang merupakan contoh gambar dan bukan contoh gambar. Sedangkan untuk kelas eksperimen 2 yang hanya menerapkan pendekatan saintifik siswa hanya mengetahui contoh dari materi yang terdapat di LKPD, sehingga peserta didik kelas eksperimen 1 lebih aktif dan lebih memahami materi dari kelas eksperimen 2 pada saat proses pembelajaran berlangsung.

Selama proses pembelajaran pada kedua kelas sampel dilaksanakan berdasarkan Rencana Pelaksanaan Pembelajaran (RPP) yang telah direncanakan sebelumnya. Proses belajar mengajar pada kelas eksperimen 1 peserta didik lebih baik dan lebih banyak berinteraksi antar peserta didik lainnya dan peserta didik tidak ada yang sibuk sendiri dalam satu kelompok. Semuanya terlibat dalam diskusi dengan kelompoknya masing-masing sehingga semua peserta didik lebih memahami materi yang diajarkan. Hal ini didukung oleh 
hasil posttest yang dilaksanakan pada pertemuan terakhir penelitian, yaitu dari 31 siswa yang mengikuti posttest terdapat 26 orang peserta didik yang memiliki nilai diatas kriteria ketuntasan minimal (KKM). Hal ini diartikan bahwa $83 \%$ nilai posttest peserta didik mencapai KKM.

Namun, peneliti masih mengalami kendala pada saat belajar mengajar berlangsung selama proses pembelajaran dengan menggunakan model pembelajaran kooperatif Examples Non Examples, diantaranya adalah kurangnya waktu pada awal pembelajaran karena harus menjelaskan kartu yang dibagikan, sehingga pada tahap kesimpulan pembelajaran kurang tersampaikan secara maksimal. Tetapi pada pembelajaran selanjutnya peserta didik pada kelas eksperimen 1 mulai memahami kartu examples non examples sehingga dapat meminimalisir waktu.

Pada pelaksanaan pembelajaran dengan pendekatan Saintifik masih banyak kendala yang dialami peneliti dalam proses pembelajaran. Ada beberapa peserta didik yang pemalas dan mengganggu peserta didik lainnya sehingga proses belajar mengajar menjadi tidak kondusif.

Beberapa peserta didik tersebut malas berpikir sehingga dalam satu kelompok ada beberapa orang peserta didik yang tidak memahami penyelesaian soal. Dengan adanya kendala pada kelas eksperimen 2 maka proses pembelajaran tidak maksimal yang menyebabkan hasil belajar peserta didik rendah. Hal ini didukung oleh data nilai posttest, yaitu dari 30 peserta didik yang mengikuti posttest hanya enam orang peserta didik yang memiliki nilai diatas kriteria ketuntasan minimal (KKM). Hal ini diketahui bahwa hanya $20 \%$ siswa yang mencapai KKM.
Peneliti telah mengatasi hal tersebut dengan membimbing peserta didik yang mengalami kesulitan dan memotivasi peserta didik yang tidak bersemangat belajar.

\section{PENUTUP \\ SIMPULAN}

Berdasarkan penelitian yang telah dilakukan pada siswa kelas VII SMP Negeri 14 Kota Bengkulu pada materi sifat-sifat bangun datar segiempat dan perhitungan data dapat disimpulkan adanya perbandingan pembelajaran menggunakan model pembelajaran examples non examples dengan pendekatan saintifik dan pembelajaran yang hanya menggunakan pendekatan saintifik dengan nilai rata-rata hasil perhitungan pengujian hipotesis dengan menggunakan uji-t menyatakan nilai $t_{\text {hitung }}>F_{\text {tabel }}$ yaitu $11,7>$ 1.698.

\section{SARAN}

Berdasarkan hasil penelitian. Saran yang dapat diberikan oleh peneliti ialah :

1. Untuk guru agar dapat menggunakan model pembelajaran examples non examples dengan pendekatan saintifik dalam pembelajaran matematika agar siswa tidak bosan dan siswa menjadi lebih keritis dalam memahami materi pada saat proses pembelajaran berlangsung.

2. Untuk peserta didik agar menjadi Bahan masukan untuk lebih termotivasi dalam mempelajari matematika khususnya pokok bahasan bangun datar segiempat.

3. Untuk peneliti agar menambah pengalaman dan wawasan dalam membangun motivasi belajar peserta didik di SMP Negeri 14 Kota Bengkulu terutama pada materi pembelajaran 
matematika yang dianggap sulit oleh siswa dengan menerapkan model pembelajaran examples non examples dengan pendekatan saiintifik, dibandingkan hanya menerapkan pendekatan saintifiknya saja.

\section{DAFTAR PUSTAKA}

Huda, Miftahul. 2017. Model-model

Pengajaran dan Pembelajaran.

Yogyakarta: Pustaka Pelajar.

Jakni. 2016. Metodologi Penelitian Eksperimen

Bidang Pendidikan. Bandung: Alfabeta

Nugroho, Wanda Yanuarto. 2016.

Example and Non-Example Pada

Pembelajaran Matematika. Jurnal

pendidikan. Forum Pendagogik Vol.

VI. No 01. 2016

Sani, R.A.2014. Pembelajaran Saintifik.

Jakarta: PT Bumi Aksara

Sugiyono. 2012. Statistik Non Parametris.

Bandung: Alfabeta

.2017. Statistika Untuk Penelitian.

Bandung: Alfabeta

Tasari, J Dris. 2011. Matematika Untuk SMP dan MTs Kelas VII. Jakarta: Pusat

Kurikulum dan Perbukuan, Kementrian

Pendidikan Nasional

Yudhanegara, M. R. dan Lestari, K. E. (2017).

Penelitian Pendidikan Matematika.

Bandung: Refika Aditama. 